\title{
A new strategy for taste masking of azithromycin antibiotic: development, characterization, and evaluation of azithromycin titanium nanohybrid for masking of bitter taste using physisorption and panel testing studies
}

This article was published in the following Dove Press journal: Drug Design, Development and Therapy

\author{
Fazli Amin,' Shahzeb \\ Khan, ${ }^{1,2}$ Syed Muhammad \\ Hassan Shah, ${ }^{3}$ Haroon \\ Rahim, ${ }^{3}$ Zahid Hussain, ${ }^{4}$ \\ Muhammad Sohail, ${ }^{5}$ Riaz \\ Ullah, ${ }^{6,7}$ Mansour S Alsaid, ${ }^{6}$ \\ Abdelaaty A Shahat ${ }^{6,8}$ \\ 'Department of Pharmacy, University \\ of Malakand, Khyber Pakhtunkhwa, \\ Pakistan; ${ }^{2}$ Department of Pharmaceutical \\ Sciences, School of Health Sciences, \\ University of KwaZulu Natal, Westville \\ 4000, Durban South Africa; ${ }^{3}$ Department \\ of Pharmacy, Sarhad University of \\ Science and Information Technology, \\ Peshawar, Khyber Pakhtunkhwa, Pakistan; \\ ${ }^{4}$ Faculty of Pharmacy, Department of \\ Pharmaceutics, Universiti Teknologi \\ MARA, Selangor, Malaysia; ${ }^{5}$ Department \\ of Pharmacy, COMSATS, Abbottabad, \\ Khyber Pakhtunkhwa, Pakistan; \\ ${ }^{6}$ Medicinal, Aromatic \& Poisonous Plants \\ Research Center (MAPPRC), College of \\ Pharmacy, King Saud University, Riyadh \\ I|45I, Saudi Arabia; 'Department of \\ Chemistry, Government College Ara \\ Khel FR, Kohat, Khyber Pakhtunkhwa, \\ Pakistan; ${ }^{8}$ Phytochemistry Department, \\ National Research Centre, Dokki, \\ Giza, Egypt
}

Correspondence: Shahzeb Khan Department of Pharmacy, University of Malakand, Chakdara 23050, Khyber Pakhtunkhwa, Pakistan

Tel +92 3459492869

Email shahzeb_333@hotmail.com
Background: The obnoxious bitter taste of orally taken antibiotics is one of the biggest problems in the treatment of children. The pediatric population cannot tolerate the bitter taste of drugs and vomit out which ultimately leads to suboptimal therapeutic value, grimace and mental stress so it is the challenging task for the formulation scientists to formulate a palatable formulation particularly to overcome address the issue.

Purpose of study: The study aimed to mask and evaluate the unpleasant bitter taste of azithromycin (AZ) in the dry suspension dosage form by physisorption technique.

Materials and methods: $\mathrm{AZ}$ was selected as an adsorbent and titanium dioxide nanoparticles as adsorbate. The $\mathrm{AZ}$ nanohybrids (AZN) were prepared by treating fixed amount of adsorbent with a varied amount of adsorbate, prepared separately by dispersing it in an aqueous medium. The mixture was sonicated, stirred followed by filtration and drying. The AZN produced were characterized by various techniques including scanning electron microscopy (SEM), energy dispersive X-rays (EDX), powder X-ray diffraction (PXRD), HPLC and Fourier-transformed infrared (FTIR). The optimized nanohybrid was blended with other excipients to get stable and taste masked dry suspension dosage form.

Results: The results confirmed the adsorption of titanium dioxide nanoparticles on the surface of AZ. The fabricated optimized formulation was subjected for taste masking by panel testing and accelerated stability studies. The results showed a remarkable improvement in bitter taste masking, inhibiting throat bite without affecting the dissolution rate. The product showed an excellent stability both in dry and reconstituted suspension. The optimized formulation of AZN and was found stable when subjected to physical and chemical stability studies, this is because of short and single step process which interns limits the exposure of the product to various environmental factors that could potentially affect the stability of the product. The dissolution rate of the optimized formulation of AZN was compared with its marketed counterpart, showing the same dissolution rate compared to its marketed formulation.

Conclusion: The current study concludes that, by fabricating AZ-titanium nanohybrids using physisorption can effectively mask the bitter taste of the drug. The palatability and stability of azithromycin formulation was potentially enhanced without affecting its dissolution rate.

Keywords: azithromycin, AZ, titanium dioxide nanoparticles, TNPs, azithromycin- $\mathrm{TiO}_{2}$ nanohybrid, AZN, dissolution, physisorption 


\section{Introduction}

The oral liquid dosage form is the most convenient dosage form for the treatment of pediatric and geriatric population as it can be administered easily. Poor solubility, unpleasant taste, stability, and bioavailability are the major issues associated with oral liquid dosage form. ${ }^{1}$ The obnoxious bitter taste is one of the biggest problems in completing the treatment in children and sensitive patients because most of the population cannot tolerate the bitter taste of drugs and vomit out, which ultimately leads to suboptimal therapeutic value, grimace, and mental stress. ${ }^{2-4}$

Taste masking is the challenging task for the formulation scientists during preformulation as well as the final formulation of liquid oral dosage form, especially suspension. Different approaches have been used to overcome these issues, which include micronization, spheronization, encapsulation, ion exchange, granulation, use of taste potentiators, taste suppressant, sweeteners, and flavors. ${ }^{5-8}$ Among these conventional techniques, the simplest and frequently used approach for taste masking of a pediatric formulation is the addition of flavor and sweeteners; however, it is not successful for highly bitter drugs such as quinine, azithromycin (AZ), clarithromycin, and vancomycin. ${ }^{9}$

$\mathrm{AZ}$ is a macrolide antibiotic, frequently used in the pediatric population for acute bacterial sinus, otitis media, pharyngitis, tonsillitis, pneumonia, bronchitis, and skin infections. ${ }^{10-12} \mathrm{AZ}$ is practically insoluble in water but soluble at saliva $\mathrm{pH}$, which readily solubilizes the drug content and expose to taste buds of tongue and feel bitter. ${ }^{13-17}$

This study aimed to mask the bitter taste of AZ (Figure 1) in the form of dry suspension. In the current study, the extreme bitter taste of the drug was masked through new and novel approach of physisorption using Langmuir isotherm and ordered mixing in which very fine particles adsorb onto the surface of coarse particles due to surface energies. ${ }^{18,19}$ Titanium dioxide nanoparticles (TNPs) were selected as an

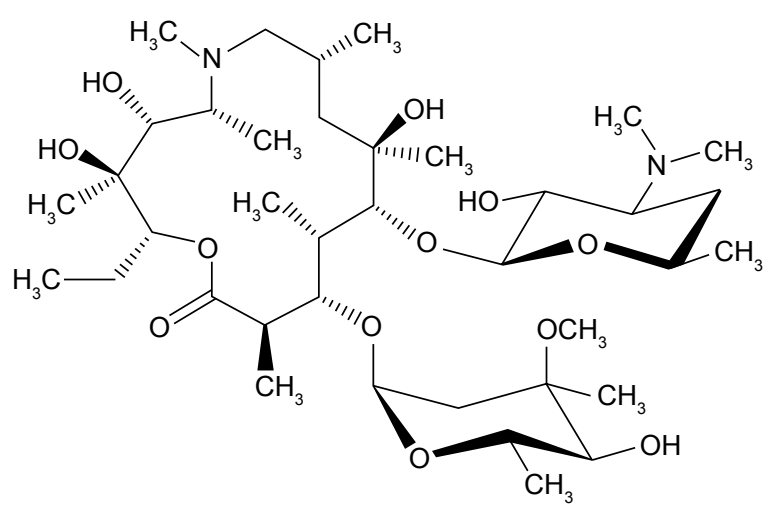

Figure I Chemical structure of azithromycin. adsorbate as it is insoluble in saliva $\mathrm{pH}$, is biocompatible, have a wide range of safety margin, and act as a nanoantibiotic for oral hygiene. ${ }^{20,21} \mathrm{~A}$ nanoantibiotic is a nanomaterial that either show antimicrobial activity by themselves or elevate the effectiveness and safety of antibiotics administration. ${ }^{22}$ $\mathrm{AZ}$ is treated as an adsorbent. ${ }^{23}$ TNPs are adsorbed onto $\mathrm{AZ}$, which acts as a shield, making a film around AZ, and as a result, drug release is retarded in the buccal cavity and the extreme bitterness is completely masked by avoiding interaction with the taste receptors of tongue; however, both the drug and the TNP adsorbed were solubilized in the intestinal $\mathrm{pH}$ where it releases the drug that becomes bioavailable. ${ }^{24,25}$

\section{Materials and methods}

\section{Materials}

AZ (Lot No HS 29415000), TNPs (Anatase; Lot No MKBC4889), and hydroxy propyl methyl cellulose (HPMC) were purchased from Sigma-Aldrich Co., St Louis, MO, USA. Xanthan gum, tribasic sodium phosphate, colloidal silicon dioxide, sodium benzoate, methyl paraben, and propyl paraben were gifted by Bryon Pharmaceutical (Pvt) Ltd, 48-Industrial Estate Peshawar, KPK, Pakistan. Analytical HPLC grade acetonitrile, methanol, tetrabutylammonium phosphate, phosphoric acid, and ammonium phosphate monoacid were purchased from Merck \& Co., Inc., Whitehouse Station, NJ, US.

\section{Methods}

\section{Preparation of AZ nanohybrids (AZN)}

The AZNs were prepared by physisorption technique. In this method, $2 \% \mathrm{w} / \mathrm{v}$ stock suspensions of $\mathrm{AZ}$ and $0.5 \% \mathrm{w} / \mathrm{v}$ suspension of $\mathrm{TiO}_{2}$ nanosuspension were prepared separately by dispersing it in an aqueous medium. The ultrasonication of the produced suspensions was carried out for 5 minutes at ultrasonic inputs ( $200 \mathrm{~W}$ ) at a pause of 3 seconds followed by stirring at $300 \mathrm{rpm}$ for 30 minutes at $25^{\circ} \mathrm{C}-30^{\circ} \mathrm{C}$. A number of dilutions containing fixed amount $(200 \mathrm{mg} / 10 \mathrm{~mL})$ of the stock suspension containing $\mathrm{AZ}$ were treated with varied dilutions of titanium dioxide stock suspension. Each mixture was stirred for 4 hours using magnetic stirrer at 1,500 rpm at room temperature followed by filtration (Whatman 42). The unadsorbed nanoparticles of each sample were filtered, and the residue left on the surface of filter paper was dried and kept for characterization and further studies.

\section{Characterization}

\section{Scanning electron microscopy (SEM)}

The particle size (PS) and morphology of unprocessed AZ, TNP, and AZN were analyzed by SEM (Model: Qunata 
$400 \mathrm{FEI}$ ) at $500 \times$ and 5,000× magnification levels, respectively. ${ }^{26-28}$ The samples of AZ and TPN were prepared for SEM studies by fixing the samples in a metal stub using an adhesive double-sided tape.

\section{Fourier-transformed infrared (FTIR)}

The molecular complex of AZ, TNP, and AZN was crushed to fine powder using an agate mortar and pestle. The fine powdered samples were mixed with potassium bromide ( $1 \%$ wt ratio) and pressed hydraulically under pressure of 8 tons to make a disk. Potassium bromide (KBr) disks were analyzed using FTIR (Bruker IFS-55, 140 Germany) between 4,000 and $400 \mathrm{~cm}^{-1}$ region. ${ }^{29,30}$

\section{Energy-dispersive X-ray (EDX)}

The optimized sample of AZN was prepared for EDX studies by fixing the samples in a metal stub using an adhesive double-sided tape. The cobalt stub was used to calibrate the machine. The parameters were included on low-vacuum beam gas with a path length of $11 \mathrm{~m}$, gas type-water 4KPS as the accusation rate, and dead time selected under 50\%. EDX analysis was done to determine the elemental and the phase composition of AZN. ${ }^{28,31}$

\section{X-ray diffraction (XRD)}

The samples of unprocessed AZ, TNP, and optimized AZNs were evaluated using X-ray powder diffraction (PANalytical, $X$ 'pert Powder). The detector was scanned over $2 \theta$ angles at a step size of $0.01^{\circ}$ step time of 10 seconds..$^{28}$

\section{Adsorption efficiency}

Adsorption efficiency of drug- $\mathrm{TiO}_{2}$ was calculated by taking the various concentrations of $\mathrm{TiO}_{2}$ with a known amount of AZ to get optimized AZN. The drug adsorption efficiency of all treated nanohybrids was quantified for adsorbed nanoparticles using the method reported by Zubata et al. ${ }^{32}$ Accurately weighed quantity of each sample of a binary system containing drug and adsorbed nanoparticles was dissolved in a solution of buffer with $\mathrm{pH}$ 6.8, and the final concentration was made to $5 \mu \mathrm{g} / \mathrm{mL}$. The solutions were filtered and analyzed by HPLC Shimadzu Model LC-10ATVP (Shimadzu Corporation, Kyoto, Japan) with Hypersil BDS C18 (250×4.6 mm) column. The gradient mobile phase composed of acetonitrile, methanol, and buffer with $\mathrm{pH} 8$ at a ratio of 20:20:60 was used. The drug adsorption efficiency was calculated.

\section{Adsorption equilibrium study}

The adsorption equilibrium study was conducted using the Langmuir adsorption isotherm to calculate the adsorption potential of TNPs onto the surface of the drug macromolecule
(AZ). Various concentrations of stock suspension containing AZ (0.040, 0.080, 0.120, 0.160, 0.20, 0.280, 0.360, and 0.40 $\mathrm{mM} / \mathrm{L})$ were treated with TNP as the adsorbate $(0.0313$, $0.0469,0.0626,0.0783,0.0939,0.1096,0.1252,0.1409$, 0.1565 , and $1.7216 \mathrm{mM}$ ) in separate $50-\mathrm{mL}$ stoppered volumetric flasks. The flasks were then stirred at $1,500 \mathrm{rpm}$ for 4 hours at $37^{\circ} \mathrm{C} \pm 0.5^{\circ} \mathrm{C}$. The samples were withdrawn at a specified time, filtered, and dried at $40^{\circ} \mathrm{C}$ for 2 hours. The prepared nanohybrids were then subjected to equilibrium concentration (Ceq) of the drug to get maximum adsorption of the TNP on to the surface of drug particles by constructing Langmuir adsorption isotherm model. ${ }^{33-35}$

$$
y=\frac{X}{m}=\frac{K \cdot n \cdot \mathrm{Ceq}}{1+n \cdot \mathrm{Ceq}},
$$

where $y$ represents the amount of TNP $(\mathrm{mM}), X / m$ is the TNP adsorbed $(X)$ per gram of $\mathrm{AZ}(m), K$ is the association constant $(\mathrm{L} / \mathrm{mM})$, Ceq represents the equilibrium constant of the drug $(\mathrm{mM} / \mathrm{L})$, and $\mathrm{n}$ represents the maximum amount of TNP adsorbed to form the monolayer during experiment ( $\mathrm{mM} / \mathrm{g}$ ).

\section{Formulation of $A Z N$}

The optimized fabricated AZN-7 was selected for conversion to dry suspension. Different formulations were prepared from AZN-7 (equivalent to $200 \mathrm{mg}$ of AZ) and mixed with various concentrations of excipients to get a stable, taste masked dry suspension. All the formulation components including AZN and excipients were dried at $40^{\circ} \mathrm{C}$ separately for 1 hour, sifted through mesh 60, and mixed thoroughly. The dry mixture was transferred to amber glass bottles for further studies.

\section{In vitro dissolution}

In vitro dissolution studies of optimized AZNs (AZN-7), its formulations (F1 to F10), and pure drug (AZ) were determined at saliva $\mathrm{pH} 6.8$ and also at intestinal $\mathrm{pH} 7.4$ using USP dissolution apparatus II at $50 \mathrm{rpm}$ at $37^{\circ} \mathrm{C}$. The samples were analyzed using the method reported by Zubata et $\mathrm{al}^{32}$ as discussed above.

The reconstituted suspension containing an equivalent amount of AZ (200 mg) from each formulation, AZ, and AZN-7 were added to the dissolution medium ( $\mathrm{pH}$ 7.4). An equivalent amount of marketed suspension was also analyzed under the same condition for comparative studies. The samples were withdrawn at the specific time of intervals $(10,20,30,40,50$, and 60 minutes). The sink conditions were maintained by replacing with the fresh medium of the same amount. The withdrawn samples were suitably diluted, filtered with Whatman filter paper 42, and quantitatively assayed. 


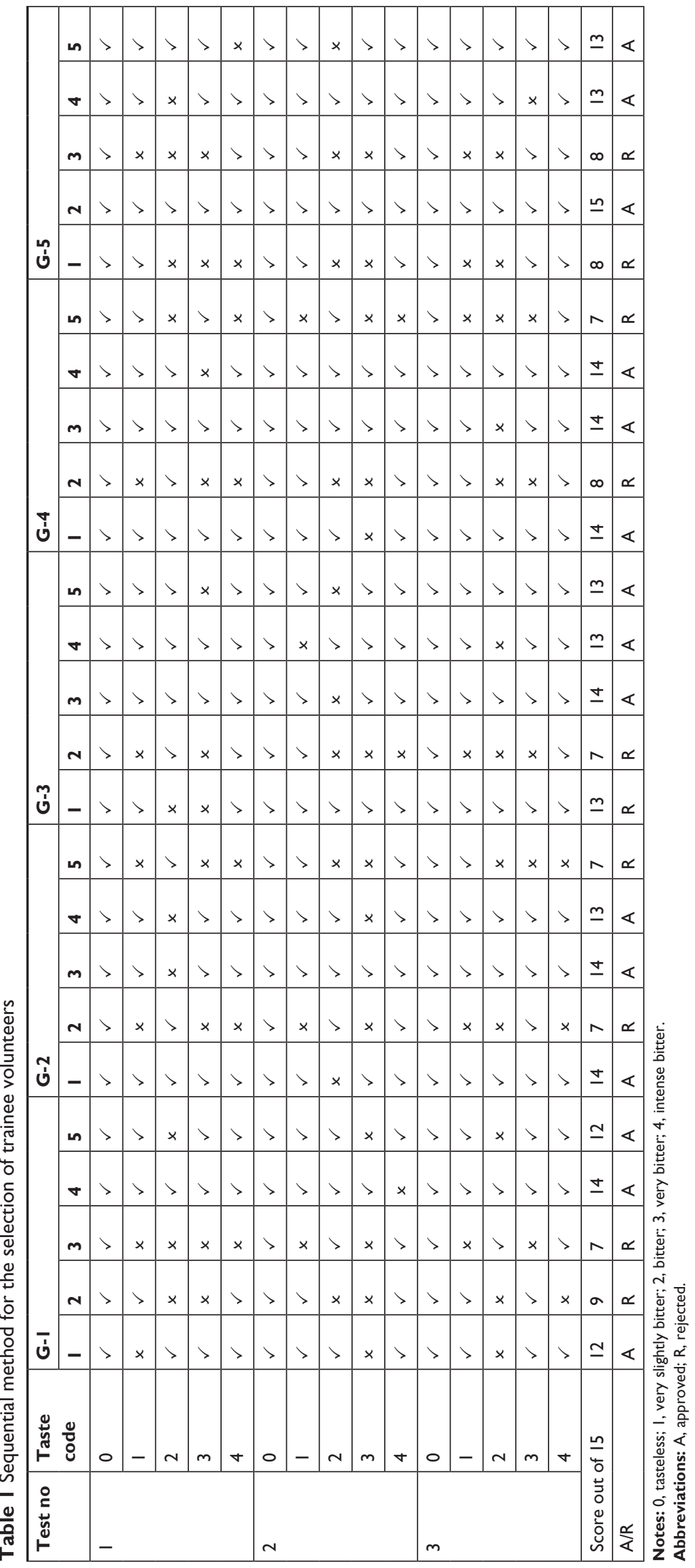




\section{Taste masking evaluation}

The taste masking study was conducted using human volunteers. All the experimental work on children for taste evaluation was conducted under the approved protocols vide Ref. No LKH/Paeds/01/17 by the Ethical Committee of Agency Headquarter Hospital Landikotal, Khyber Pakhtunkhwa, Pakistan. It is also important to mention that the designed study was conducted in accordance with the Declaration of Helsinki. Prior to conduct the taste masking evaluation studies using human volunteers, the written signed consent proformas were collected from each volunteer.

In the current research, volunteers were selected by sequential method (Table 1). ${ }^{36,37}$ The taste identification and palatability of all batches F1 to F10 were evaluated by panel testing. ${ }^{38}$

The sequential test for taste evaluation was performed to analyze and interpret sensory evaluation for the selection of trainee volunteers for panel testing of the final formulation taste evaluation. In this method, stock suspension containing 3.0, 2.0, and $1.0 \mathrm{~mL}$ and blank suspension having no AZ (blank) were prepared by dispersing in distilled water. Each level of taste ranging from tasteless to intense bitter was given numeric values from 0 to 4 .

In this evaluation method, a total of 25 volunteers divided into five groups were tested for taste threshold and correct evaluation of different tastes. In total, $5 \mathrm{~mL}$ of each stock suspension was given randomly to each volunteer in every set of test. The supertasters and nontasters were rejected through sequential tests. Of 25 trainees, 15 volunteers were approved.

The selected 15 volunteers were again divided into five groups and each group consisted of three volunteers. The panel testing method was chosen to evaluate the bitterness of all formulations (F1-F10). In this method, the same procedure as that of sequential method was followed and ranking made on the scale of perception ranging from 0 to 3 , with 0 being tasteless and 3 marked as bitter.

\section{Stability studies}

Chemical and accelerated stability studies were performed on the optimized formulation of $\mathrm{F} 6$ for both dry and reconstituted suspension as per ICH guidelines. ${ }^{39}$ The required quantity of optimized formulation (F6) batch was kept for physical and chemical stability in a tightly closed amber glass bottle at $40^{\circ} \mathrm{C} \pm 2{ }^{\circ} \mathrm{C}$ and $75 \% \pm 5 \% \mathrm{RH}$ in the stability chamber for 90 days. The reconstituted samples were kept at refrigeration for 14 days, and the physical and chemical stabilities were analyzed quantitatively for active contents as per schedule.

\section{Results and discussion Optimized AZNs}

The AZNs were prepared by physisorption technique. A known quantity of $A Z$ was treated with the varied dilution of TNP. The theoretical drug loading, experimental drug loading, and percent drug entrapment efficiency were calculated for 10 samples as shown in Table 2. The results in Table 2 exhibited that the AZN-7 was found effective having maximum drug entrapment capacity when the concentration of $\mathrm{TiO}_{2}$ was $93.6 \% \pm 1.3 \%$. This showed that $\mathrm{TiO}_{2}$ nanoparticles were sufficiently adsorbed onto the surface of AZ particles as reported by Khan et $\mathrm{al},{ }^{40}$ which in case of nanoparticles adsorption onto the carrier particles, at a particular concentration of the adsorbate, the surface of adsorbent becomes saturated where there is no chance for the small particles to be further attached onto the surface of adsorbent. The optimized nanohybrid (AZN-7) was selected for further studies including its formulation on the basis of maximum

Table 2 Preparation of AZNs

\begin{tabular}{|c|c|c|c|c|c|c|}
\hline $\begin{array}{l}\text { Formulation } \\
\text { code }\end{array}$ & $\begin{array}{l}\text { Quantity of AZ } \\
(2 \% w / v)\end{array}$ & $\begin{array}{l}\text { Titanium dioxide } \\
\text { nanosuspension } \\
(0.25 \% \mathrm{w} / \mathrm{v})\end{array}$ & $\begin{array}{l}\text { Theoretical wt } \\
\text { of AZ+TNP ( } \mathrm{mg})\end{array}$ & $\begin{array}{l}\text { Theoretical drug } \\
\text { loading (\%) }\end{array}$ & $\begin{array}{l}\text { Experimental } \\
\text { drug loading (\%) }\end{array}$ & $\begin{array}{l}\text { Adsorption } \\
\text { efficiency (\%) }\end{array}$ \\
\hline AZN-I & $10 \mathrm{~mL}(200 \mathrm{mg})$ & $\mathrm{I} \mathrm{mL}(2.5 \mathrm{mg})$ & 202.50 & 98.76 & $85.3 \pm 1.2$ & $86.37 \pm 2.2$ \\
\hline AZN-2 & $10 \mathrm{~mL}(200 \mathrm{mg})$ & $1.5 \mathrm{~mL}(3.75 \mathrm{mg})$ & 203.75 & 98.15 & $85.7 \pm 1.6$ & $87.3 I \pm I .5$ \\
\hline AZN-3 & $10 \mathrm{~mL}(200 \mathrm{mg})$ & $2 \mathrm{~mL}(5 \mathrm{mg})$ & 205.00 & 97.56 & $86.2 \pm 1.3$ & $88.35 \pm 2.0$ \\
\hline AZN-4 & $10 \mathrm{~mL}(200 \mathrm{mg})$ & $2.5 \mathrm{~mL}(6.25 \mathrm{mg})$ & 206.25 & 96.96 & $87.5 \pm 1.2$ & $90.24 \pm 1.6$ \\
\hline AZN-5 & $10 \mathrm{~mL}(200 \mathrm{mg})$ & $3 \mathrm{~mL}(7.5 \mathrm{mg})$ & 207.50 & 96.38 & $88.6 \pm 1.7$ & $91.92 \pm 1.8$ \\
\hline AZN-6 & 10 mL (200 mg) & $3.5 \mathrm{~mL}(8.75 \mathrm{mg})$ & 208.75 & 95.80 & $89.7 \pm 1.4$ & $93.63 \pm 2.2$ \\
\hline AZN-7 & $10 \mathrm{~mL}(200 \mathrm{mg})$ & $4 \mathrm{~mL}(10 \mathrm{mg})$ & 210.00 & 95.23 & $93.6 \pm 1.3$ & $98.28 \pm 1.3$ \\
\hline AZN-8 & 10 mL (200 mg) & $4.5 \mathrm{~mL}$ (I I .25 mg) & 211.25 & 94.67 & $91.8 \pm 1.3$ & $96.96 \pm 2.3$ \\
\hline AZN-9 & $10 \mathrm{~mL}(200 \mathrm{mg})$ & $5 \mathrm{~mL}$ (12.5 mg) & 212.5 & 94.11 & $88.5 \pm 1.5$ & $94.03 \pm 2.5$ \\
\hline$A Z N-10$ & 10 mL (200 mg) & $5.5 \mathrm{~mL}(13.75 \mathrm{mg})$ & 213.75 & 93.56 & $88.0 \pm 1.3$ & $94.05 \pm 2.4$ \\
\hline
\end{tabular}

Abbreviations: AZ, azithromycin; AZNs, azithromycin nanohybrids; TNP, Titanium dioxide nanoparticle. 

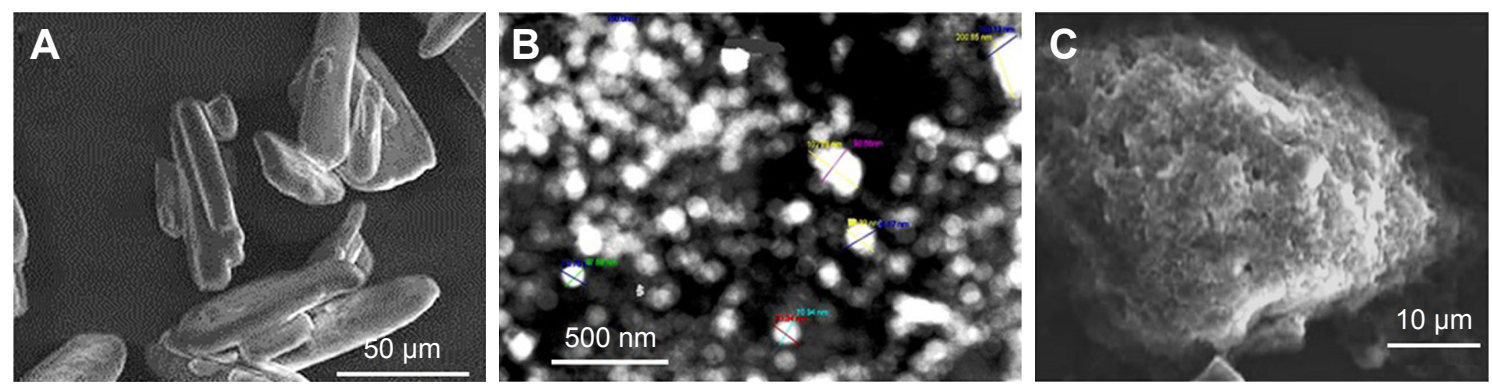

Figure 2 (A) Scanning electron micrographs of unprocessed azithromycin, (B) titanium dioxide nanoparticles, and (C) azithromycin nanohybrid.

adsorption of nanoparticles on the surface of the drug with the help of entrapment efficiency. The effectiveness of the adsorption using entrapment efficacy was also previously studied by Aboutaleb et al. ${ }^{41}$

\section{SEM}

The SEM images of all samples of AZNs and TNPs were taken. The studies showed that the $\mathrm{PS}$ of $\mathrm{TiO}_{2} \mathrm{NPs}$ was found in the range of 70-200 nm. It appears in agglomerates as shown in Figure 2B. The cubic-shaped crystals with sharp and elongated edges were observed for $\mathrm{AZ}$ having average dimensions between 10 and $150 \mu \mathrm{m}$ as shown in Figure 2A. The SEM studies showed that the TNPs were successfully adsorbed on the surface of AZ (Figure 2C). Furthermore, the SEM image of the recovered AZN (Figure 2C) also showed that the surface has been covered by a whitish sheet of TNPs. The adsorption isotherm also confirmed the adsorption. ${ }^{33,34}$ The equilibrium time adsorption of TNPs on to the surface of macromolecule (AZ) was achieved within 2 hours without loss of active drug content and adhesion to the wall of glasswares like flasks and other accessories. The maximum adsorption of the TNPs was recorded as $2.6 \mathrm{mM} / \mathrm{g}$, whereas the Ceq of the drug was established at $0.115 \mathrm{mM} / \mathrm{L}$ of the solution as shown in Figure 3. The Ceqs of

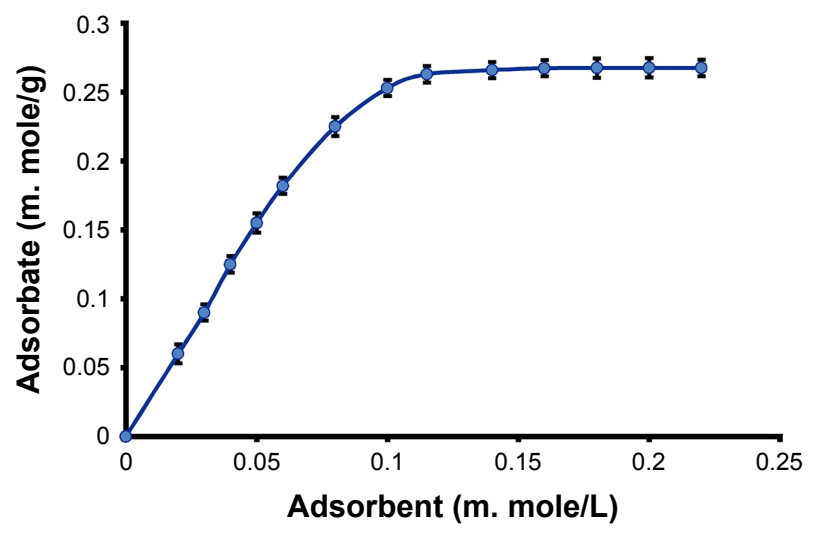

Figure 3 Langmuir adsorption isotherm of AZ and TNP equilibrium. Abbreviations: AZ, azithromycin; TNP, titanium dioxide nanoparticles. the drug and adsorbate (TNP) were 0.280 and $0.1252 \mathrm{mM} / \mathrm{g}$, respectively, which corresponds to $10 \mathrm{mg}$ of adsorbed TNP onto the surface of $200 \mathrm{mg}$ of AZ. Furthermore, after this concentration $(10 \mathrm{mg})$, no free sites were available on the surface of AZ to adsorb any more TNP.

\section{Evaluation of AZ-TNP complex by FTIR}

The results of AZNs (Figure 4B) showed distinct peaks at 3,491.16, 2,970.38, 2,931.80, 1,720.50, 1,377.17, 1,188.15, $1,165.0,1,083.99,1,049.28$, and $995.27 \mathrm{~cm}^{-1}$. Similarly, the FTIR spectrum of unprocessed AZ (Figure 4A) showed distinct peaks at the same position as that observed for AZN, ie, 3,556.74, 3,491.16, 2,970.38, 2,931.80, 1,720.50, $1,462.04,1,377.17,1,188.15,1,083.99,1,049.28$, and $991.41 \mathrm{~cm}^{-1}$, respectively. The results clearly showed and confirmed that no interaction occurred due to adsorption of TNPs (Figure 4C) on AZ. The same distinct peaks for $\mathrm{AZN}$ and $\mathrm{TiO}_{2}$ have also been previously reported by other researchers. ${ }^{30,42}$

\section{EDX}

EDX confirmed the presence of both $\mathrm{AZ}$ and $\mathrm{TiO}_{2}$ compounds. The peaks of titanium were observed at $0.5,4.51$, and $4.9 \mathrm{keV}$ as this energy is found in the electron transition of $\mathrm{TiO}_{2}{ }^{43}$ Peaks of carbon (C) and oxygen (O) were seen as these two elements were found in $\mathrm{AZ}$ adsorbed by titanium dioxide, as shown in Figure 5. ${ }^{44}$ In addition to microscopic and HPLC studies, the EDX study was also found very useful to confirm the presence of both adsorbate and adsorbent in the recovered samples.

\section{Powder XRD studies}

The XRD results showed that the unprocessed AZ was crystalline in nature (Figure 6B). However, the peak intensities of AZNs were relatively low compared to its unprocessed API (Figure 6C). This is due to the adsorption of TNP that has a smaller PS, which causes the reduction in peak intensity of AZN as shown in Figure 6A. The results clearly showed that AZ maintained its crystallinity after physisorption with TNP. ${ }^{40,45}$ 
Furthermore, in nanocomposite-type structures, where the small particles become the components of the microparticles, the peak intensities can potentially be reduced.

\section{Formulation of optimized AZN}

The optimized AZN was formulated in the form of dry suspension by using different excipients in various concentrations. The results in Table 3 show that $\mathrm{F} 6$ formulation exhibited excellent results when subjected to different studies including physicochemical, content uniformity, and dissolution studies. As shown in Table 4, formulation F6 showed excellent results of the active content assay, in vitro dissolution (Figure 7A-D), and taste acceptability (Tables 1 and 5).
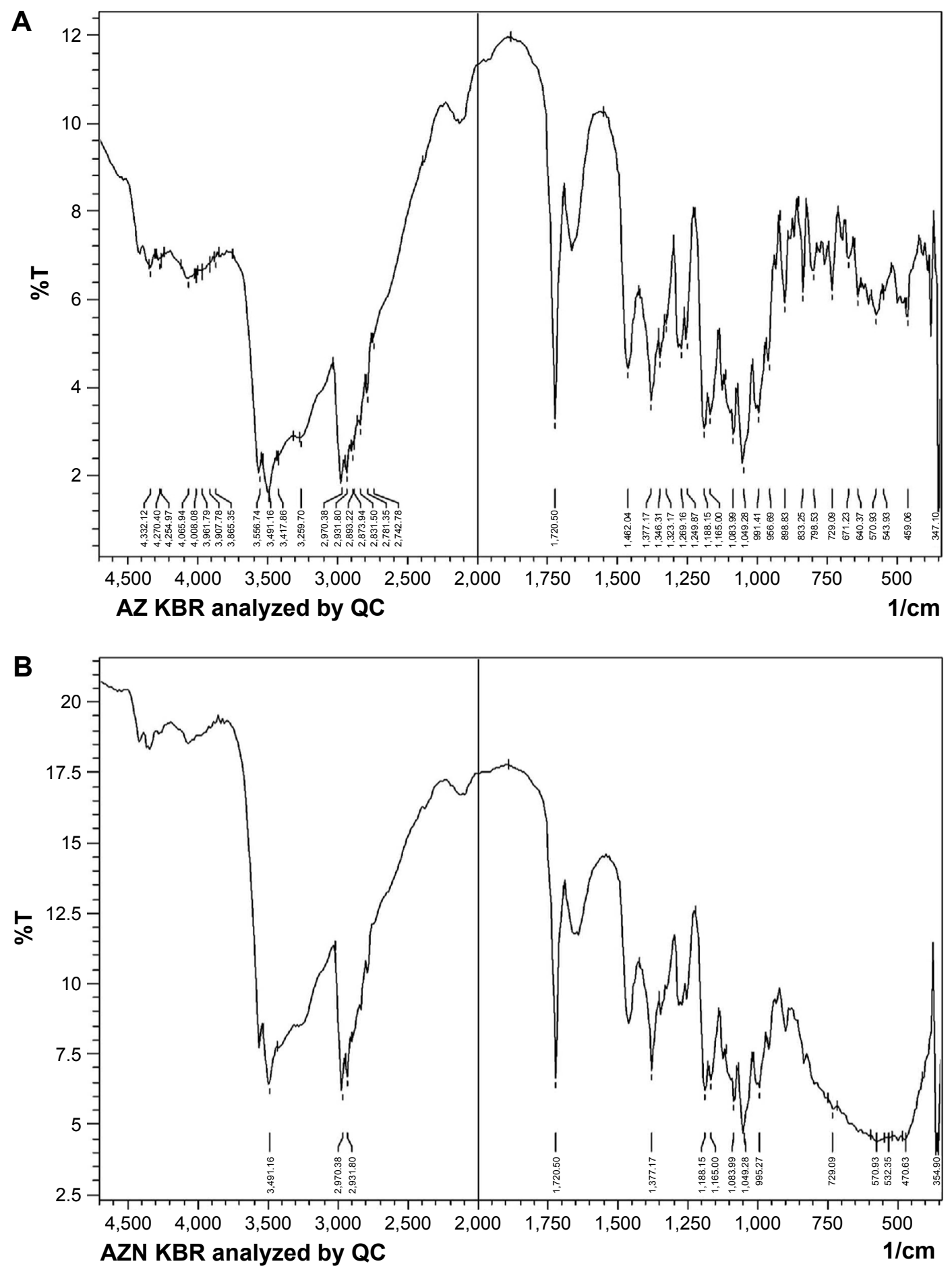

Figure 4 (Continued) 


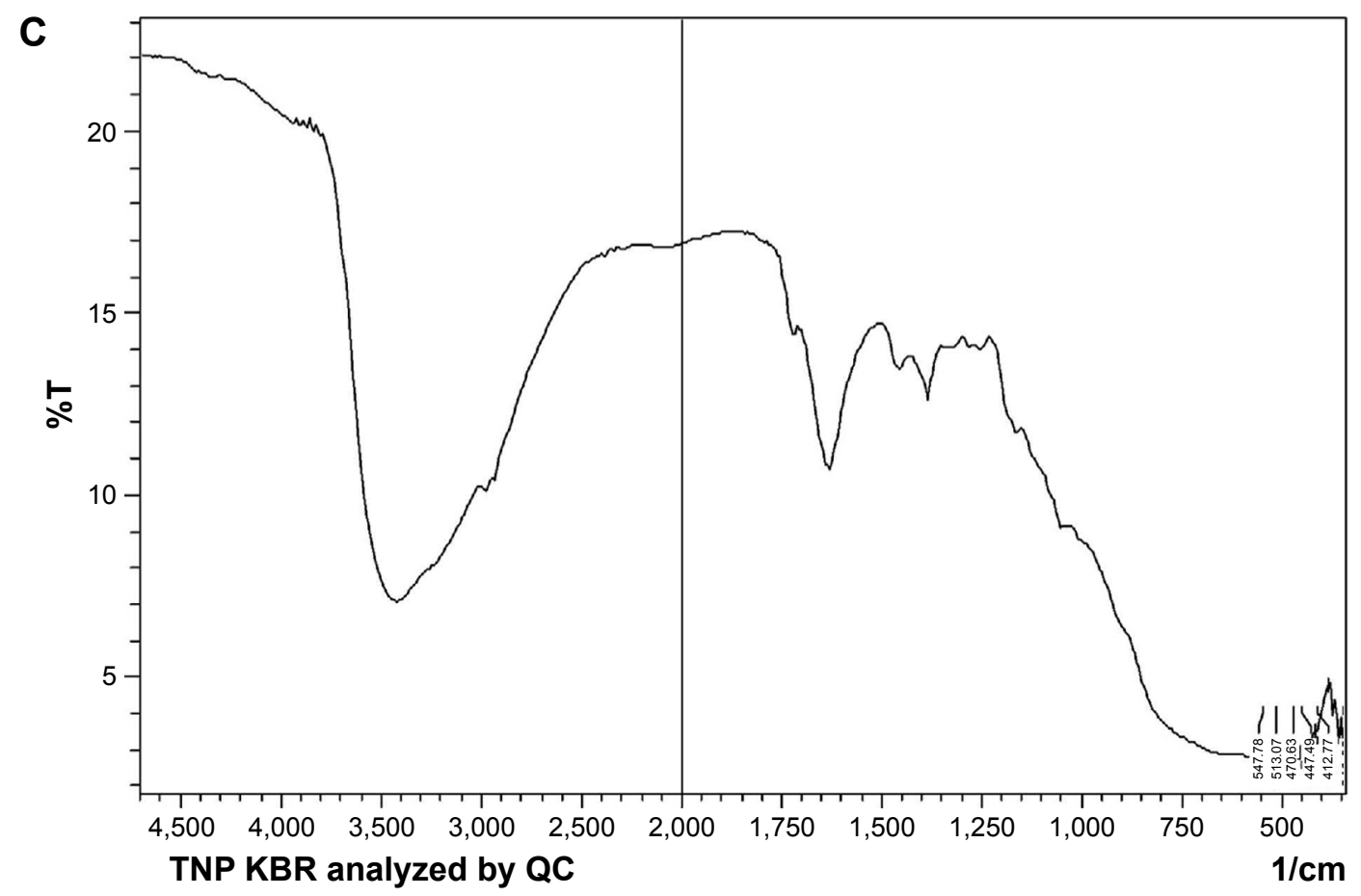

Figure 4 (A) Fourier-transformed infrared spectrum of unprocessed azithromycin, (B) azithromycin nanohybrid, and (C) titanium dioxide nanoparticles. Abbreviations: AZN, azithromycin nanohybrids; TNP, titanium dioxide nanoparticle.

\section{In vitro dissolution}

The drug release pattern of AZ, optimized nanohybrid (AZN-7), and its various formulations (F1-F10) were analyzed using phosphate buffer $\mathrm{pH}$ 7.4. The formulation (F6) showed an excellent dissolution rate among all formulation and declared as optimized formulation, as mentioned in Figure 7B, whereas formulations $\mathrm{F} 1$ to $\mathrm{F} 5$ showed lesser dissolution rate, as shown in Figure 7A, due to the lesser ratio of xanthan gum and HPMC used. The dissolution rate of optimized formulation was compared with its marketed formulation at intestinal $\mathrm{pH}$ (7.4), as shown in Figure 7C. The dissolution rate of optimized formulation was initially slightly delayed in the first 30 minutes, while at the end of dissolution process (60 minutes), both the AZN optimized formulation and its marketed drug exhibited the same

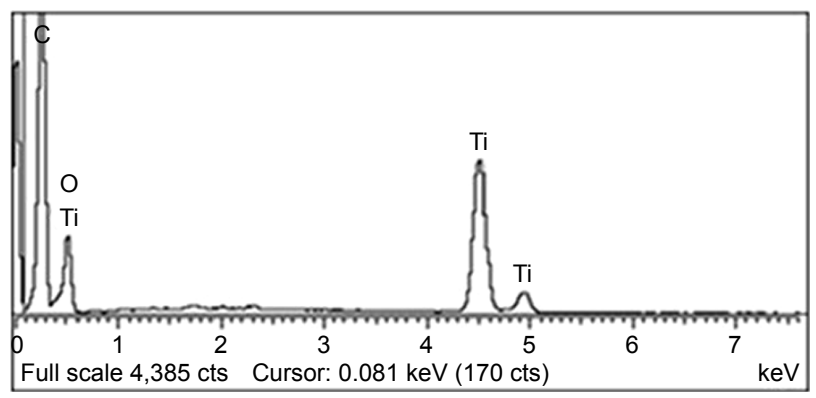

Figure 5 EDX of azithromycin nanohybrid. Abbreviation: EDX, energy-dispersive X-ray. dissolution rate. This delay in dissolution rate is due to adsorption of TNP on the surface of AZ. However, this compensation of the dissolution rate was due to the faster rate of dissolution of the TNPs at $\mathrm{pH} 7.4$, which resulted in maximum availability of the drug (AZ) in the medium. At the same time, the sample containing equivalent amount of $A Z N$ and $A Z$ raw material was also run, which showed a retarded and delayed dissolution rate when compared with that of optimized formulation and marketed drug taken as standard for comparison. The excipients have shown a

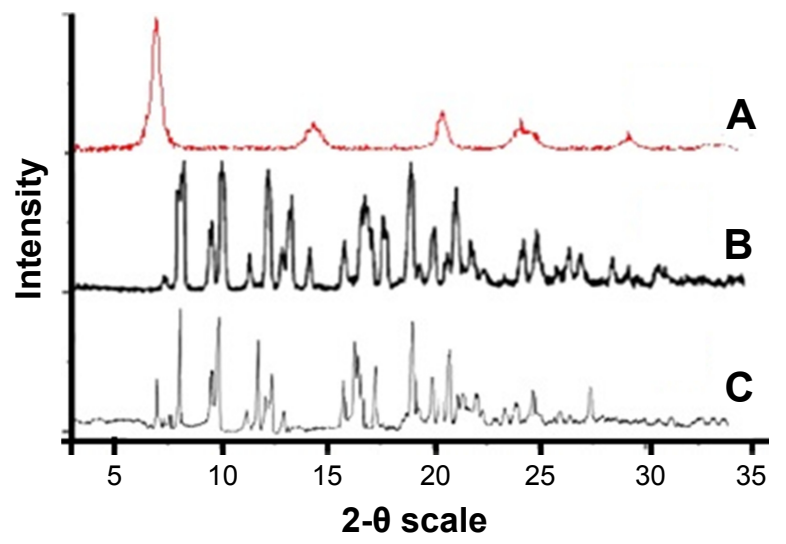

Figure 6 (A) X-ray powder diffraction pattern of TNP, (B) AZ unprocessed, (C) AZN.

Abbreviations: AZ, azithromycin; AZN, azithromycin nanohybrids; TNPs, titanium dioxide nanoparticles. 
Table 3 Formulation of AZN

\begin{tabular}{|c|c|c|c|c|c|c|c|c|c|c|}
\hline \multirow[t]{2}{*}{ Ingredient } & \multicolumn{10}{|c|}{ Dry suspension final formulation codes and strength $(\mathrm{g} / \mathrm{I} 5 \mathrm{~mL})$} \\
\hline & FI & $\mathbf{F 2}$ & $\mathbf{F 3}$ & F4 & F5 & F6 & F7 & $\mathbf{F 8}$ & F9 & FIO \\
\hline$(A Z N-7) \cong A Z$ & 0.6 & 0.6 & 0.6 & 0.6 & 0.6 & 0.6 & 0.6 & 0.6 & 0.6 & 0.60 \\
\hline $\begin{array}{l}\text { Tribasic sodium } \\
\text { phosphate }\end{array}$ & 0.03 & 0.03 & 0.03 & 0.03 & 0.045 & 0.045 & 0.045 & 0.060 & 0.060 & 0.060 \\
\hline Sodium benzoate & 0.03 & 0.03 & 0.04 & 0.04 & 0.055 & 0.055 & 0.055 & 0.060 & 0.065 & 0.070 \\
\hline $\begin{array}{l}\text { Colloidal silicon } \\
\text { dioxide }\end{array}$ & 0.03 & 0.04 & 0.05 & 0.06 & 0.070 & 0.080 & 0.09 & 0.10 & 0.11 & 0.12 \\
\hline Xanthan gum & 0.0025 & 0.0035 & 0.0045 & 0.0055 & 0.0065 & 0.0075 & 0.0085 & 0.0095 & 0.010 & 0.015 \\
\hline Methyl paraben & 0.002 & 0.002 & 0.002 & 0.002 & 0.002 & 0.002 & 0.002 & 0.002 & 0.002 & 0.002 \\
\hline Propyl paraben & 0.001 & 0.001 & 0.001 & 0.001 & 0.001 & 0.001 & 0.001 & 0.001 & 0.001 & 0.001 \\
\hline HPMC & 0.0005 & 0.0005 & 0.0006 & 0.0006 & 0.0007 & 0.0007 & 0.0008 & 0.0008 & 0.0009 & 0.0009 \\
\hline
\end{tabular}

Abbreviations: AZ, azithromycin; AZN, azithromycin nanohybrids; HPMC, hydroxy propyl methyl cellulose.

positive effect on dissolution rate in all developed dry suspension dosage forms. In addition, the designed dissolution studies to evaluate the impact of adsorbed nanoparticles on masking the bitter taste of $\mathrm{AZ}$ resulted in retarded rate at saliva $\mathrm{pH}$ both for the AZN and the respective developed dry suspension (F6). The AZN and for the optimized formulation F6 showed a delayed and retarded release when analyzed at saliva pH 6.8 (Figure 7D). This retarded dissolution rate is due to insolubility of the adsorbed TNP onto the surface of the AZ at saliva $\mathrm{pH} 6.8 \cdot{ }^{46-48}$ Owing to complete coverage of the surface of AZ by TNPs, the interaction of AZ and receptors in taste buds can potentially be reduced and consequently the bitter taste is masked. In addition, there was also observed retarded dissolution rate for the marketed formulation of AZ compared with the bare AZ. However, the retarded dissolution rate of marketed formulation of $A Z$ was less compared with F6 formulation and AZN. This shows that in our formulations, the surface of $\mathrm{AZ}$ was strongly protected by adsorption of TNPs from the outer medium compared with the marketed formulation.

\section{Stability studies}

The results showed that both the dry suspension and reconstituted optimized formulation (F6) met the specification and were found stable when subjected to physical and chemical stability studies (Tables 4 and 6 ). The stability of the AZN formulation is because of short and single-step process, which in turn limits the exposure of the product to various environmental factors that could potentially affect the stability of the product. In addition to the above factors, TNP that physically covers the surface of AZ also added to its stability. To get maximum stability, the dry suspension is recommended to be stored below $30^{\circ} \mathrm{C}$ away from the light and moisture, whereas the reconstituted suspension is advised to keep at $2^{\circ} \mathrm{C}-8^{\circ} \mathrm{C} .{ }^{28,49,50}$

\section{Taste masking evaluation}

The selected volunteers were provided the prepared formulations for panel testing to get the optimized product. As shown in Tables 1 and 5, the optimized formulation (F6) exhibited an excellent result and showed excellent palatability compared to its counterparts. This study substantiated the results of dissolution studies, where AZN and F6 showed retarded dissolution rates at saliva $\mathrm{pH}$ compared with the bare $\mathrm{AZ}$ and marketed drug. It was also confirmed from the SEM images (Figure 2C) that TNP was completely adsorbed on the surface of $\mathrm{AZ}$, which effectively forms a layer, thereby masking the intense bitter taste of AZ.

Table 4 Physicochemical stability of azithromycin as dry suspension (F6)

\begin{tabular}{|l|l|l|l|l|l|l|l|l|}
\hline & Day 0 & Day 2 & Day 4 & Day 6 & Day 8 & Day I0 & Day I2 & Day I4 \\
\hline \% active content & 99.68 & 98.94 & 97.98 & 97.42 & 96.77 & 95.98 & 95.14 & 94.18 \\
\hline Viscosity (mPa s) & 310.6 & 310.6 & 310.6 & 310.5 & 310.5 & 310.4 & 310.4 & 310.2 \\
\hline pH & 8.0 & 8.0 & 8.0 & 8.0 & 8.0 & 8.0 & 7.9 & 7.9 \\
\hline Redispersion & Good & Good & Good & Good & Good & Good & Good & Good \\
\hline Taste & Palatable & Palatable & Palatable & Palatable & Palatable & Palatable & Palatable & Palatable \\
\hline
\end{tabular}


A

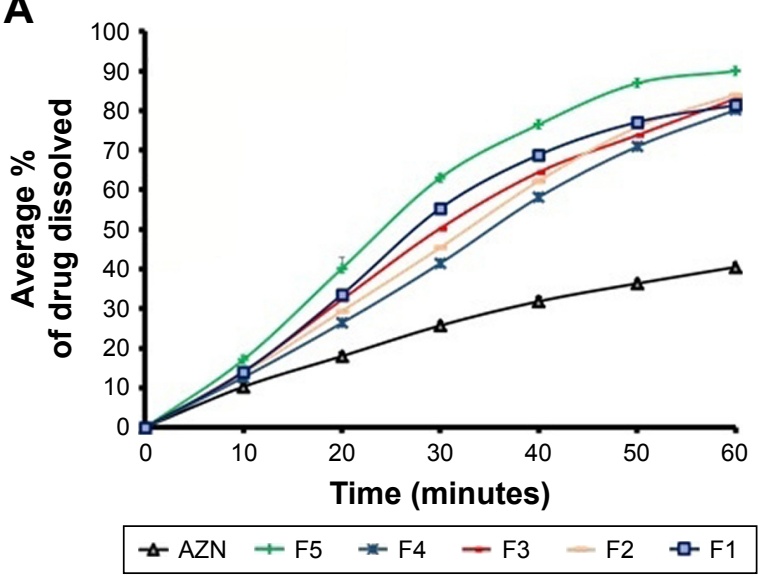

C

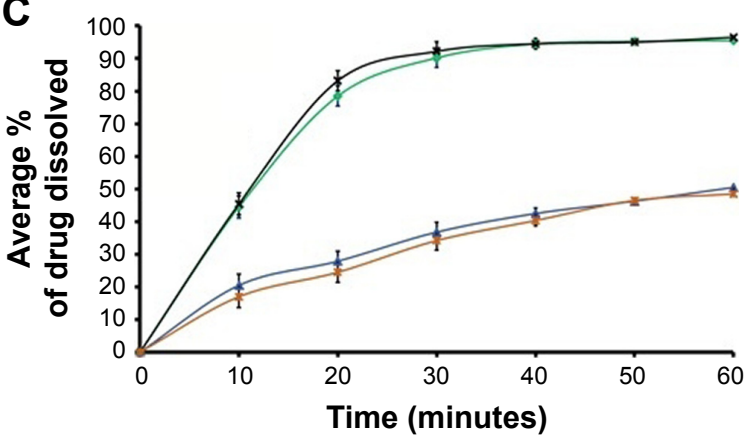

$\rightarrow \mathrm{F} 6 \neq \mathrm{AZ} *$ Standard $\rightarrow \mathrm{AZN}$
B

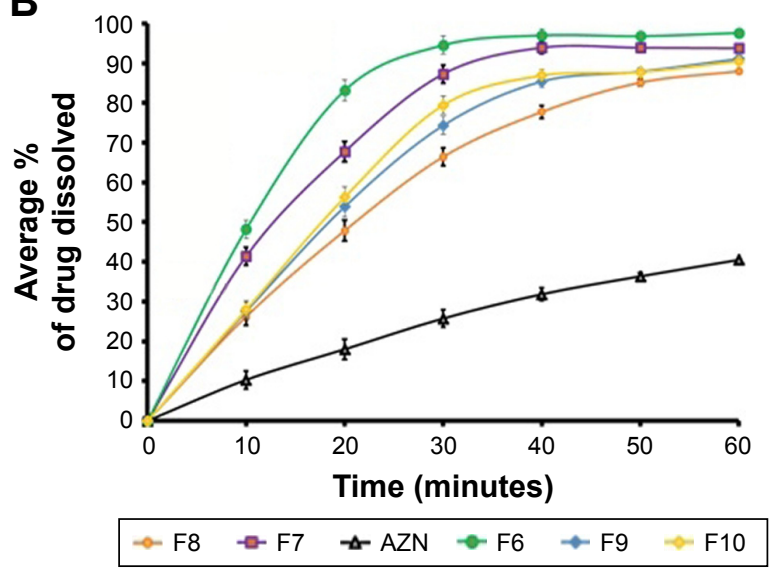

D

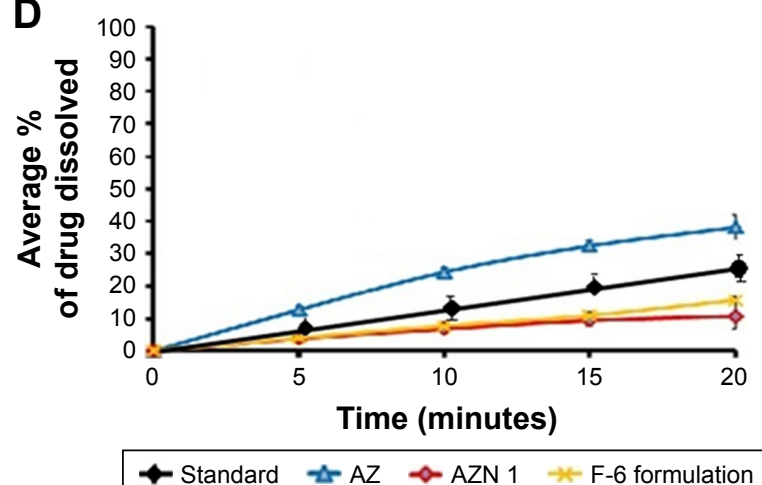

Figure 7 (A) Dissolution rate of formulations (FI-F5) and AZN at pH 7.4. (B) Dissolution rate of formulations (F6-FI0) and AZN. (C) Comparative dissolution rate of optimized formulation (F6), marketed drug, AZN, and unprocessed AZ at pH 7.4. (D) Comparative dissolution rate of unprocessed AZ, AZN, standard (marketed) AZN, and optimized formulation (F6) at saliva $\mathrm{pH}$.

Abbreviations: AZ, azithromycin; AZN, azithromycin nanohybrids.

\section{Conclusion}

The novel approach of physisorption was successfully used to fabricate AZN in the form of dry suspension using biocompatible TNPs as adsorbate; the palatability of $\mathrm{AZ}$ was potentially enhanced when evaluated on numbers of volunteers after passing the sequential test. The $\mathrm{AZ}$ optimized formulation (F6) showed a similar dissolution rate compared to its marketed product at intestinal $\mathrm{pH}$, whereas the release

Table 5 Panel testing for taste evaluation of various formulations

\begin{tabular}{|c|c|c|c|c|c|c|c|c|c|c|c|c|c|c|c|}
\hline \multirow{2}{*}{$\begin{array}{l}\text { Formulation code } \\
\text { FI }\end{array}$} & \multicolumn{3}{|c|}{ Group I } & \multicolumn{3}{|c|}{ Group 2} & \multicolumn{3}{|c|}{ Group 3} & \multicolumn{3}{|c|}{ Group 4} & \multicolumn{3}{|c|}{ Group 5} \\
\hline & 0 & I & 2 & 1 & 0 & 1 & 1 & I & 1 & 1 & 2 & 0 & I & I & I \\
\hline F2 & I & 0 & 1 & 2 & I & 0 & & 1 & 0 & 1 & 1 & 1 & 2 & $\mathrm{I}$ & 0 \\
\hline F3 & 0 & I & 1 & 0 & I & $\mathrm{I}$ & 0 & 1 & 2 & 1 & 0 & 1 & I & 0 & 0 \\
\hline F4 & I & 0 & 1 & 0 & I & 1 & 0 & 0 & 2 & 1 & I & 0 & I & 0 & I \\
\hline F5 & 0 & 0 & 1 & 2 & 0 & 1 & 1 & 0 & 1 & I & 0 & 1 & 0 & I & 0 \\
\hline F6 & 0 & 0 & 0 & 1 & 0 & 0 & 0 & 0 & 0 & 0 & 0 & 0 & 0 & I & 0 \\
\hline F7 & 0 & 0 & 0 & 1 & 0 & 0 & 0 & 0 & 0 & 1 & $\mathrm{I}$ & 0 & 0 & $\mathrm{I}$ & 0 \\
\hline F8 & I & 0 & 0 & 0 & 2 & 0 & 1 & 0 & 1 & 1 & 0 & 1 & 0 & $\mathrm{I}$ & 0 \\
\hline F9 & 0 & I & 0 & 1 & 0 & 1 & 0 & 0 & 1 & 0 & I & 0 & I & 0 & 0 \\
\hline FIO & I & 0 & 0 & 1 & 0 & 1 & 0 & 1 & 1 & 0 & 1 & 0 & 2 & I & 0 \\
\hline
\end{tabular}

Note: Taste code: 0 , palatable; I, very slightly bitter; 2 , bitter after taste; 3 , bitter. 
Table 6 Stability study of optimized formulation (F6) after reconstitution kept at $8^{\circ} \mathrm{C}-15^{\circ} \mathrm{C}$

\begin{tabular}{|l|l|l|l|l|}
\hline \multirow{2}{*}{ Tests } & Time period & Day 30 & Day 60 & Day 90 \\
\cline { 2 - 5 } & Day 0 & $99.63 \pm 1.50$ & $99.58 \pm 0.68$ & $99.56 \pm 0.82$ \\
\hline Assay (active content) & $99.67 \pm 1.25$ & 310.6 & 310.4 & 310.5 \\
\hline Viscosity (mPa s) & 310.6 & 8.0 & 8.0 & 7.9 \\
\hline $\mathrm{pH}$ & 8.0 & Good & Good & Good \\
\hline Powder flow & Good & Good & Good & Good \\
\hline Dispersion & Good & & \\
\hline
\end{tabular}

Note: Values of active contents are expressed as $\% \pm S D ; n=3$.

rate of the optimized formulation was retarded at saliva $\mathrm{pH}$. This retarded dissolution rate was due to $\mathrm{TiO}_{2}$, which acts as a protective layer on $\mathrm{AZ}$, and due to short residual time in the oral cavity that is $20-40$ seconds for pediatric oral dosage form. The adsorbed nanoparticle completely acts as a barrier between drug and taste buds of the tongue, thus inhibiting the bitter taste. It is also concluded that due to the adsorption of TNP, the product showed long-term physicochemical stability when stored for 90 days. The reconstituted suspension meets the specification when kept at refrigerated conditions for 15 days; this may be due to the protection of drug from the light due to the adsorption of nanoparticles. It has been concluded from the current study that controlling the processes and condition for optimization is the key for fabrication of the AZN to achieve maximum palatability.

\section{Acknowledgments}

The authors extend their appreciation to the Deanship of Scientific Research at King Saud University for funding the work through the research group no. RGP-262. The authors gratefully acknowledge Department of Pharmacy, University of Malakand, Chakdara, Dir (L), Khyber Pakhtunkhwa, Pakistan and Department of Pharmacy, Faculty of Life Sciences, Sarhad University, Peshawar, Khyber Pakhtunkhwa, Pakistan.

\section{Disclosure}

The authors report no conflicts of interest in this work.

\section{References}

1. Nunn T, Williams J. Formulation of medicines for children. Br J Clin Pharmacol. 2005;59(6):674-676.

2. Steiner JE. Human facial expressions in response to taste and smell stimulation. Adv Child Dev Behav. 1979;13:257-295.

3. Suzuki H, Onishi H, Takahashi Y, Iwata M, Machida Y. Development of oral acetaminophen chewable tablets with inhibited bitter taste. Int J Pharm. 2003;251(1-2):123-132.

4. Kendrick JG, Ma K, Dezorzi P, Hamilton D. Vomiting of oral medications by pediatric patients: survey of medication redosing practices. Can J Hosp Pharm. 2012;65(3):196-201.
5. Sharma S, Lewis S. Taste masking technologies: a review. Int J Pharm Pharm Sci. 2010;2(2):6-13.

6. Barnard AS, Zapol P, Curtiss LA. Modeling the morphology and phase stability of $\mathrm{TiO} 2$ nanocrystals in water. $J$ Chem Theory Comput. 2005;1(1):107-116.

7. Abraham J, Mathew F. Taste masking of paediatric formulation: a review on technologies, recent trends and regulatory aspects. Int $J$ Pharm Pharm Sci. 2014;6(1):12-19.

8. Ganesh G, Manjusha P, Gowthamarajan K, et al. Design and development of buccal drug delivery system for labetalol using natural polymer. Int J Pharmaceut Res Dev. 2011;3(3):37-49.

9. Panovská Z, Šedivá A, Jedelská M, Pokorný J. Effect of ethanol on interactions of bitter and sweet tastes in aqueous solutions. Czech $J$ Food Sci. 2008;26(No 2):139-145.

10. Wallach JV. Structure Activity Relationship (SAR) Studies of Arylcycloalkylamines as N-Methyl-D-Aspartate Receptor Antagonists [Ph.D. thesis]. Philadelphia, PA: University of the Sciences; 2014.

11. Maskell JP, Sefton AM, Williams JD. Comparative in-vitro activity of azithromycin and erythromycin against Gram-positive cocci, Haemophilus influenzae and anaerobes. J Antimicrob Chemother. 1990; 25(Suppl_A):19-24.

12. Fiese EF, Steffen SH. Comparison of the acid stability of azithromycin and erythromycin A. J Antimicrob Chemother. 1990;25(Suppl_A): 39-47.

13. Ng TBP. Auditors' decisions on audit differences that affect significant earnings thresholds. Audit J Pract Theor. 2007;26(1): $71-89$.

14. Woldum HS, Larsen KL, Madsen F. Cyclodextrin controlled release of poorly water-soluble drugs from hydrogels. Drug Deliv. 2008;15(1): 69-80.

15. Arora SC, Sharma PK, Irchhaiya R, Khatkar A, Singh N, Gagoria J. Development, characterization and solubility study of solid dispersions of cefuroxime axetil by the solvent evaporation method. J Adv Pharm Technol Res. 2010;1(3):326.

16. Aps JK, Martens LC. Review: the physiology of saliva and transfer of drugs into saliva. Forensic Sci Int. 2005;150(2-3):119-131.

17. Aframian DJ, Davidowitz T, Benoliel R. The distribution of oral mucosal pH values in healthy saliva secretors. Oral Dis. 2006;12(4): 420-423.

18. Ismail M, Weng CN, Rahman HA, Zakaria NA. Freundlich isotherm equilibrium equastions in determining effectiveness a low cost absorbent to heavy metal removal in wastewater (leachate) at Teluk Kitang Landfill, Pengkalan Chepa, Kelantan, Malaysia. J Geogr Earth Sci. 2013;1(1):1-8.

19. Saharan VA, Kukkar V, Kataria M, Kharb V, Choudhury P. Ordered mixing: mechanism, process and applications in pharmaceutical formulations. Asian J Pharm Sci. 2008;3(6):240-259.

20. Khan ST, Al-Khedhairy AA, Musarrat J. ZnO and TiO2 nanoparticles as novel antimicrobial agents for oral hygiene: a review. J Nanopart Res. 2015;17(6):276. 
21. Kalaiarasi S, Jose M. Streptomycin loaded TiO2 nanoparticles: preparation, characterization and antibacterial applications. J Nanostructure Chem. 2017;7(1):47-53.

22. Huh AJ, Kwon YJ. "Nanoantibiotics": a new paradigm for treating infectious diseases using nanomaterials in the antibiotics resistant era. $J$ Control Release. 2011;156(2):128-145.

23. Weir A. Titanium Dioxide Nanomaterials: Human Exposure and Environmental Release [master's thesis]. Tempe, AZ: Arizona State University; 2011.

24. Roche EJ; Johnson and Johnson Consumer Inc, assignee. Taste masking and sustained release coatings for pharmaceuticals. United States patents US 5075114. 1991 Dec 24.

25. Balarak D, Mostafapour F, Azarpira H, Joghataei A. Langmuir, Freundlich, Temkin and Dubinin-radushkevich isotherms studies of equilibrium sorption of ampicilin unto montmorillonite nanoparticles. J Pharm Res Int. 2017;20(2):1-9.

26. Wen T, Gao J, Shen J, Zhou Z. Preparation and characterization of TiO2 thin films by the sol-gel process. J Mater Sci. 2001;36(24): 5923-5926.

27. Fagundes JG Jr, da Silva Manera R, Tokimatsu RC, Ventrella VA, Gallego J. Application of titanium machining chips in welding consumables for wear-resistant hardfacing. Weld Int. 2016;30(7): 520-526.

28. Rahim H, Sadiq A, Khan S, et al. Aceclofenac nanocrystals with enhanced in vitro, in vivo performance: formulation optimization, characterization, analgesic and acute toxicity studies. Drug Des Devel Ther. 2017;11:2443-2452.

29. Shet N, Vaidya I. Formulation and evaluation of taste masked suspension of azithromycin dihydrate. Curr Pharma Res. 2013; 4(1): 1072 .

30. Kauss T, Gaubert A, Boyer C, et al. Pharmaceutical development and optimization of azithromycin suppository for paediatric use. Int $J$ Pharm. 2013;441(1-2):218-226.

31. Boehme M, Fu G, Ionescu E, Ensinger W. Fabrication of anatase titanium dioxide nanotubes by electroless deposition using polycarbonate for separate casting method. Nanomicro Lett. 2010;2(1):26-30.

32. Zubata P, Ceresole R, Rosasco MA, Pizzorno MT. A new HPLC method for azithromycin quantitation. J Pharm Biomed Anal. 2002;27(5): 833-836.

33. Ng C, Losso JN, Marshall WE, Rao RM. Freundlich adsorption isotherms of agricultural by-product-based powdered activated carbons in a geosmin-water system. Bioresour Technol. 2002;85(2):131-135.

34. Steve K, Erika T, Reynold T, Paul M. Activated carbon: a unit operations and processes of activated carbon. Environ Eng. 1998;25: $350-749$.
35. Giammar DE, Maus CJ, Xie L. Effects of particle size and crystalline phase on lead adsorption to titanium dioxide nanoparticles. Environ Eng Sci. 2007;24(1):85-95.

36. Vahčić N, Hruškar M. Sekvencijalni testovi u odabiru članova panel grupe. Mljekarstvo: časopis za unaprjeđenje proizvodnje i prerade mlijeka. 1998;48(2):97-104.

37. Meilgaard MC, Carr BT, Civille GV. Sensory Evaluation Techniques. Boca Raton, FL: CRC Press; 1999.

38. Shishu, Kamalpreet, Kapoor VR. Development of taste masked oral formulation of ornidazole. Indian J Pharm Sci. 2010;72(2):211.

39. Grimm W. Extension of the International Conference on Harmonization Tripartite Guideline for Stability Testing of New Drug Substances and Products to countries of climatic zones III and IV. Drug Dev Ind Pharm. 1998;24(4):313-325.

40. Khan S, de Matas M, Plakkot S, Anwar J. Nanocrystal recovery by use of carrier particles. Cryst Growth Des. 2014;14(3):1003-1009.

41. Aboutaleb A, Abdel-Rahman S, Ahmed M, Younis M. Enhancement of domperidone dissolution rate via formulation of adsorbates and co-adsorbates. Int J Pharm Sci Res. 2016;7(3):951.

42. Kotecha RK, Bhadra DS, Rajesh KS. Formulation \& process development of azithromycin ophthalmic nanosuspension. Int J Pharm Pharma Sci. 2013;5(4):490-497.

43. Sheikh F A, Macossay J, Kanjwal M, Abdal-Hay A, Tantry MA, Kim H. Titanium dioxide nanofibers and microparticles containing nickel nanoparticles. ISRN Nanomater. 2012;2012:1-8.

44. Böhme M, Fu G, Ionescu E, Ensinger W. Fabrication of anatase titanium dioxide nanotubes by electroless deposition using polycarbonate for separate casting method. Nano-Micro Lett. 2013;2:26-30.

45. Shah SM, Ullah F, Khan S, et al. Smart nanocrystals of artemether: fabrication, characterization, and comparative in vitro and in vivo antimalarial evaluation. Drug Des Devel Ther. 2016;10:3837-3850.

46. Aucamp M, Odendaal R, Liebenberg W, Hamman J. Amorphous azithromycin with improved aqueous solubility and intestinal membrane permeability. Drug Dev Ind Pharm. 2015;41(7):1100-1108.

47. Schmidt J, Vogelsberger W. Dissolution kinetics of titanium dioxide nanoparticles: the observation of an unusual kinetic size effect. J Phys Chem B. 2006;110(9):3955-3963.

48. Kramer SM, Gorichev IG, Lainer YA, Artamonova IV, Terekhova MV. Calculation of the solubility of TiO2 and titanates in sulfuric acid solutions. Russ Metall. 2014;2014(9):704-707.

49. Freitas C, Müller RH. Effect of light and temperature on zeta potential and physical stability in solid lipid nanoparticle (SLN ${ }^{\mathrm{TM}}$ ) dispersions. Int J Pharm. 1998;168(2):221-229.

50. Matthews BR. Regulatory aspects of stability testing in Europe. Drug Dev Ind Pharm. 1999;25(7):831-856.
Drug Design, Development and Therapy

\section{Publish your work in this journal}

Drug Design, Development and Therapy is an international, peerreviewed open-access journal that spans the spectrum of drug design and development through to clinical applications. Clinical outcomes, patient safety, and programs for the development and effective, safe, and sustained use of medicines are the features of the journal, which

\section{Dovepress}

has also been accepted for indexing on PubMed Central. The manuscript management system is completely online and includes a very quick and fair peer-review system, which is all easy to use. Visit http://www.dovepress.com/testimonials.php to read real quotes from published authors. 